\title{
An overview of air-sea interface process studies
}

\author{
J C LI \\ Institute of Mechanics, Chinese Academy of Sciences, Beijing, 100080, China \\ e-mail: jcli@cc5.imech.ac.cn
}

\begin{abstract}
Recent progress in the study of air-sea interface processes for momentum, heat, moisture and mass transfer are reviewed in the present article. Except for turbulent structure, we have analysed the other physical mechanisms occurring in the wave boundary layer, such as the roles of the sea surface state, droplets and bubbles due to wave breaking, which at least partly account for the existing discrepancies between theory and observations. The experiments, both over the ocean and in the laboratory, are described briefly. In conclusion, a few perspective trends in this area are suggested for further investigation.
\end{abstract}

Keywords. Air-sea interaction; wave-breaking; wave age; stratification; atmospheric boundary layer.

\section{Introduction}

Oceanic circulation, storm surges and wind waves are mainly driven by atmospheric pressure and shear stress. Tropical cyclone genesis and long-term weather forecasting are dominantly influenced by the heat and moisture exchange between air and sea. Global change and ecology research stimulate new interests in gas transfer through their interface. Theoretical study on air-sea interaction will become one of the most challenging problems in fluid mechanics as well as in atmospheric and oceanic sciences in the next century owing to the difficulties in marine observations (Kagan 1995).

The determination of coefficients in the bulk formulas, which are basically of phenomenological nature, has been an arduous task during the recent decades. Usually they are regarded as equal constants. However, the observations display apparent variation and scatter in drag, Stanton and Dalton coefficients versus wind speed (Geernaert \& Plant 1990). In addition, whether the traditional approach underestimates their values, in storm conditions is still unanswered (Bortkovskii 1987). As a matter of fact, these coefficients are not only dependent on wind speed, but also on the sea surface state and wave-breaking. Hence, the dynamic approach is obviously an appropriate way for understanding the intrinsic mechanisms. Essentially the exchange of momentum, energy and gases between air and sea is turbulent. The Monin-Obukhov similarity theory was initially used to estimate average properties, followed by the various turbulent modelling methods ( $\mathrm{Li}$ 1993). The difference from terrestrial processes lies in the fact that the air-sea interface is not only 
stochastic and at times rough, but is also mobile. Therefore, we can never exactly delineate the physics without considering surface waves, especially those breaking at high wind speed (Banner 1992; Banner \& Donelan 1992; Melville 1996).

The verification of the models available depends heavily on marine observations. The experiment involves a process from measuring air-sea fluxes locally to a more complex situation with a multi-ship international project. In the 1970's, we have seen the potential power of remote sensing from satellites and oil platforms. Scientists did not directly apply flux measurements to atmospheric and marine modelling until we needed long term and high resolution climate prediction by the end of the 1980's. The experiment in the laboratory with the wind-wave flume is an alternative to scrutinizing microprocesses in the wave boundary layer (Smith et al 1996b).

In the present paper, we are concerned with current advances in the study of air-sea interaction, focusing on the most important physical mechanisms in the process. The progress of research in this area by Chinese scientists is also covered.

\section{Air-sea interface process models}

Turbulent structures in the atmospheric boundary layer (ABL) and the oceanic boundary layer (OBL) have been described in Li's (1993) paper. ABL flows over a large expanse of water with much higher density, heat capacity and small Bowen ratio. Hence, the marine atmospheric boundary layer (MABL) is characterised by homogeneity and moistness and often exhibits nearly neutral nature except in the cold air break period. In most cases, it belongs to the category of cloud-topped boundary layer (CTBL) (Garratt 1992). In particular, wave-breaking, which gives rise to bubbles and droplets and thus exerts significant influence on the interface processes, occurs time and again at high wind speed.

\subsection{Drag coefficient and wave age}

Although scientists (Wu 1990) have paid attention to the effects of stratification on drag coefficients, the sea surface state remains the most significant factor for momentum exchange between air and sea. The roughness elements generated by wind are responsible for the larger drag. Intuitively, we can obviously see patches of whitecap and spume emerging over the sea surface. Quantitatively the sea state is measured by the so-called wave age defined as $c_{p} / u_{*}$, where $c_{p}$ is the phase speed of wind wave at its spectral peak, $u_{*}$ is the friction velocity. For young and old waves, the wave ages roughly correspond to 5 and 30 respectively. Young waves need more energy input for growth, while mature waves need relatively less energy. Based on the foregoing argument, a drag coefficient dependence on both wind speed and wave age is derived (Maat et al 1991). Recently, the idea is incorporated in the $k-\epsilon$ model, further showing that this fact is in good agreement with observations (Zhang \& Li 1997). However, the situations for shallow water or multi-peak spectrum need further revision of the theory (Geernaert 1988). 


\subsection{Heat and moisture fluxes and droplets}

The direct consequence of wave breaking is the generation of bubbles and droplets. Among them the microscale breaking is less conspicuous. The frequently occurring spilling and violent plunging breakers are always accompanied by air entrainment with bubbles diffusing into the upper mixing layer. As a bubble rises up to the surface, its burst leads to the formation of droplets of different sizes ranging from 0.1 to $100 \mu \mathrm{m}$. The models by Bortkovskii (1987) and Ling (1992) predicted considerable enhancement in heat and moisture transfer in storm conditions. Recent observations (Katsaros \& Decosmo 1993; Smith et al 1996b) in the HEXOS programme did not exhibit the sharp increase to wind speeds of $15-20 \mathrm{~m} / \mathrm{s}$ as expected by considering the evaporation of droplets in the previous models. Possible mechanism accounting for the phenomenon seems to be the reduction of the near-surface humidity gradient due to droplet evaporation, though the measurement of latent heat flux at the wind speed higher than $20 \mathrm{~m} / \mathrm{s}$ is still needed. Also, the resulting cooling of near surface air is responsible for concurrent reduction of sensible heat flux through the interface.

\subsection{Gas transfer and bubbles}

Gas fluxes through air-sea surface are not so well understood as the momentum and energy fluxes we addressed above although there are a number of models such as film models, eddy models and surface renewal models available. The demands for sustainable development give impetus to the study in this context, especially for "climate" and "ecology" gases such as $\mathrm{CO}_{2}, \mathrm{CH}_{4}, \mathrm{NH}_{3}, \mathrm{HNO}_{3}$ (Smith et al 1996a). Usually, gas fluxes are estimated by using a simple model of diffusion through the water surface microlayer, resulting in a square root dependence of exchange rate on diffusivity. It is not applicable to gas fluxes carried in bubbles. Recent investigation by Zhou \& Liu (1998) first considered the effects of small bubble groups by combining bubble motion and gas diffusion in the wave field. The supersaturation degree for oxygen is consistent with observations. If we make careful observation in the wave flume, we find that the energy-containing eddies near the surface are extremely elongated in the longitudinal direction and keep on renewing the free surface. Komori et al (1989) further established the relation between renewal frequency and burst events, indicating the roles played by coherent turbulent structures.

\section{Observations and experiments}

In the last 25 years, a great number of international programmes such as ATEX, AMTEX, JASIN, MARESN, HEXOS, CODE. FASINEX etc. have been jointly implemented. People succeeded in coping with flow distortion and developing aspirated shields to protect fast temperature and humidity sensors in measuring fluxes at higher wind speeds up to $19 \mathrm{~m} / \mathrm{s}$. On-going programmes including COARE and MBLP aim at linking mesoscale and boundary layer scale measurements (Smith et al 1996a). China has taken an active part in the activities by dispatching three ships for exploration in the tropical western Pacific region to study the characteristics of MABL there. The goal of SCSMEX is not only to understand local monsoon in the South China Sea, but also to contribute to global 
change studies by exploring microscopic air-sea surface processes (Ye \& Lin 1995). Past experiences have shown that the wind-wave flume experiment is a powerful tool for us to understand microstructure and microprocess under controlled conditions. For example, the experiment at the National Weather Research Institute, Canada, showed the minimum in the Dalton number for $\mathrm{CO}_{2}, \mathrm{H}_{2} \mathrm{O}$ as the first wind-generated wavelets occurred (Ocampo et al 1994). A new multiexposure colour image technique was developed to capture the motion of bubbles and droplets neighbouring the water surface in the wind-wave flume at the Environmental Science \& Technology Center, Institute of Mechanics, Chinese Academy of Sciences (Huhe 1996).

\section{Perspective trends}

In conclusion, a few perspective trends in this area are suggested for further investigation in air-sea interaction. To continue studies on turbulent and nonturbulent factors crucial on the microscale by combining theory and experiments in the laboratory to resolve pending issues remains the principal task. Large-eddy simulation (LES) seems a more promising and plausible approach for numerical simulation of turbulent structures in ABL in the foreseeable future. Painstaking observations at much higher wind speeds, greater than $20 \mathrm{~m} / \mathrm{s}$, should be carried out to make accurate measurements of various fluxes. We are able to rely more on satellite remote sensing by conversely estimating physical quantities at sea surface from microwave, visible and infrared light signals. In the long run, all the results obtained should be incorporated in the global and regional general circulation models for climate and ecological environment prediction.

The project is financially supported by the Chinese National Science Foundation.

\section{References}

Banner M L 1992 The importance of wave breaking on the sea surface. In Nonlinear dynamics of ocean waves (eds) A Brandt, S E Ramberg, M E Schlesinger (Singapore: World Scientific) pp 178-189

Banner M L, Donelan M A 1992 The physical consequences of wave breaking in deep water. In Breaking waves (eds) M L Banner, R Grimshaw (Berlin: Springer-Verlag) pp 1-15

Bortkovskii R S 1987 The transfer of energy and mass in spray-filled marine atmospheric boundary layer. In Air-sea exchange of heat and moisture during storms (Dordrecht: Reidel) chap. 3. pp $88-142$

Garratt J R 1992 The cloud-topped boundary layer. In The atmospheric boundary layer (Cambridge: University Press) chap. 7, pp 193-223

Geernaert G L 1988 Drag coefficient modelling for the near coastal zone. Dyn. Atmos. Oceans 11: $307-322$

Geernaert G L. Plant W J 1990 The bulk parameterizations for the wind stress and heat fluxes. In Surface waves and fluxes (Dordrecht: Kluwer) chap. 5, pp 91-172 
Huhe A D 1996 Multicolored image technique and processes method. In Proceedings of the 4th China-Japan Workshop on Flow Visualization (ed.) Q D Wei (Beijing: Peking University Press) pp 389-394

Kagan B A 1995 The present state of the climate system. In Ocean-atmosphere interaction and climate modelling (Cambridge: University Press) chap. 2, pp 45-102

Katsaros K B, Decosmo 1993 Water vapor flux from the sea at high wind speed. In Tropical cyclone disaster (eds) J Lighthill, Z M Zheng (Beijing: Peking University Press) pp 386-392

Komori S, Murakami Y, Ueda H 1989 The relationship between surface renewal and bursting motions in an open channel flow. J. Fluid Mech. 203: 103-123

Li J C 1993 Turbulence in atmosphere and ocean. In Some new trends on fluid mechanics and theoretical physics (eds) C C Lin, N Hu (Beijing: Peking University Press) pp 343-348

Ling S Q 1992 Effects of breaking waves on the transport of heat and vapor fluxes from the oceans. In Breaking waves (eds) M L Banner, R Grimshaw (Berlin: Springer-Verlag) pp 133-138

Maat N, Kraan C, Oost W A 1991 The roughness of wind waves. Boundary Layer Meteorol. 54: $89-103$

Melville W K 1996 The role of surface-wave breaking in air sea interaction. Annu. Rev. Fluid Mech. 28: 279-321

Ocampo F J, Donelan M A, Merzi N, Jia F 1994 Laboratory measurement of mass transfer of carbon dioxide and water vapor for smooth and rough flow conditions. Tellus B46: 16-32

Smith S D, Christopher W F, Geernaert G L, Hasse L 1996a Air-sea fluxes: 25 years of progress. Boundary Layer Meteorol. (25th Anniversary Volume): 247-290

Smith S D. Katsaros K B, Oost W A, Meystayer P G 1996b The impact of the Hexos programme. Boundary Layer Meteorol. (25th Anniversary Volume): 121-141

Wu J 1990 Comment on "Coefficients for sea surface wind stress, heat flux and wind profiles as a function of wind speed and temperature" by S D Smith. J. Geophys. Res. 95(C2): 1775-1776

Ye D Z, Lin H 1995 Programmes under planning. China's contribution to global change studies (Beijing: Science Press) chap. 3, pp 175-179

Zhang Z F, Li J C 1997 Numerical study on the drag coefficient of sea surface for full-developed winds. Acta Mech. Sin. 29: 385-394

Zhou X C, Liu C R 1998 Gas exchange by bubbles in waves. Chinese Phys. Lett. 15: 198-199 